\title{
In-transit Melanoma Metastases: Incidence, Prognosis, and the Role of Lymphadenectomy
}

\author{
Georgia Beasley $^{1}$ and Douglas Tyler $^{2}$ \\ ${ }^{1}$ Department of Surgery, Duke University, Durham, NC; ${ }^{2}$ Department of Surgery, University of Texas Medical Branch \\ Galveston, Galveston, TX
}

In this issue of Annals of Surgical Oncology, Read and colleagues describe a cohort analysis of the incidence, prognosis, and role of lymphadenectomy for in-transit (IT) melanoma. The study contributes to the large volume of clinical research this group has contributed to IT melanoma specifically and melanoma in general. The data they describe from a large prospectively maintained melanoma database can help clinicians understand this unusual presentation of stage 3 disease and also can be used to optimize treatment strategies for this patient population.

In their study, the incidence of IT disease was $7.8 \%$ ( $n=483 / 6211)$ among patients with primary melanomas $(>1 \mathrm{~mm})$ and $0.4 \%(n=22 / 5288)$ among patients with primary melanoma $(<1 \mathrm{~mm})$. These numbers generally are consistent with previous estimates of IT disease development, which range from 2 to $10 \% .^{1}$ The median interval between the primary diagnosis and IT disease was 17.9 months. Additionally, for $54 \%$ of patients, IT disease was the only site of recurrence, whereas $36 \%$ had IT disease plus nodal involvement, and only $10 \%$ presented concurrently with metastatic disease.

The aforementioned data also are consistent with those reported from other studies. Not surprisingly, sentinel node (SN) status and primary tumor ulceration were associated with higher incidences of IT disease in this study. The rate of IT diseases was $4.7 \%$ among SN-negative patients and $21.6 \%$ among SN-positive patients. The latter rate, which suggests that IT disease will develop in nearly one fourth (21\%) of patients with SN-positive disease, highlights the

\section{(C) Society of Surgical Oncology 2014}

First Received: 5 September 2014;

Published Online: 30 September 2014

G. Beasley

e-mail: schwe009@mc.duke.edu critical need for effective management strategies for IT disease.

Patients who present with IT disease should undergo restaging including physical exam, whole-body imaging, and possibly SN biopsy. Evaluation of the nodal basin is essential to guide therapeutic options and for prognosis. At the time of primary melanoma diagnosis, 145 patients who experienced IT disease development in the current study were initially SN negative. However, $31 \%$ subsequently experienced clinical regional nodal disease. Thus, even if a patient presenting with IT disease has a negative SN at the time of primary diagnosis, $30 \%$ may harbor nodal disease. Elective lymph node dissection for patients presenting with IT failed to show a survival benefit in this study and should not be routinely recommended.

We have previously reported the role of SN biopsy for patients presenting with IT disease and have found SN to be positive in $33 \%$ of patients with IT disease, a vast majority of whom had a negative $\mathrm{SN}$ at the time of primary melanoma. $^{2}$ The distinction between patients with and those without nodal disease may be helpful for therapy decisions (especially clinical trials) and prognosis.

In the current study, those with no regional nodal disease had a 5-year survival rate of $59 \%$ (stage $3 \mathrm{~B}$ ) compared with a survival rate of $19 \%$ (stage 3C) for those with evidence of nodal disease. Conversely, the American Joint Committee on Cancer (AJCC) database suggests a 5-year survival rate of $59 \%$ for stage $3 \mathrm{~B}$ and $40 \%$ for stage $3 \mathrm{C}$ disease. These differences are likely reflective of the strict and more precise criteria used in this Melanoma Institute of Australia study of "in-transit" disease while further highlighting the need for more effective therapies. Despite the differences in actual numbers, both rates highlight that nodal disease is associated with a poor prognosis.

Of the 190 patients in this study who presented with IT disease as the first site and only site of recurrence, $63 \%$ 
progressed to nodal or distal disease, whereas $37 \%$ never experienced any other disease during the follow-up period. This is in alignment with historical amputation studies, in which amputation (ultimate control of extremity disease) was associated with long-term survival ( $>15$ years) for 25-30\% of patients. ${ }^{3}$ Appropriately selected patients can benefit from aggressive local control of disease. Although amputation should not be advocated, selection of patients who will not experience the development of distant disease should be a focus of future research because these patients should be directed toward aggressive local treatment such as regional chemotherapy or intralesional therapy. Regional chemotherapy can be associated with complete response rates of 30-50\%, and patients achieving a CR have been shown to have a survival benefit. ${ }^{4}$ Selection of patients can be done with the aid of whole-body imaging and SN biopsy, but ultimately, an understanding of tumor biology will optimally characterize these patients accordingly.

The current study suggests that $75 \%$ of patients with IT disease will eventually experience either nodal disease, systemic disease, or both. For many patients, the IT disease is disfiguring and has an impact on quality of life due to bleeding or necrotic lesions. Treatment of the IT disease together with the nodal and metastatic disease is important in an attempt to improve overall survival and palliate patient symptoms. ${ }^{5}$

Current approaches to the treatment of patients with IT disease vary widely among surgical and medical oncology practices. Given its poor prognosis, some advocate that IT disease should be treated systemically. Targeted therapies are useful only for patients who harbor the Braf mutation, and responses, although marked, may have only an average durability of 6-10 months. ${ }^{6}$ Immunologic therapies alone can lead to impressive responses as well, but these responses may occur in only about $10-30 \%$ of patients. ${ }^{7}$ Surgical groups have more readily embraced regional therapies using both intralesional treatments and regional chemotherapy because they have tended to see the ability of these treatments to control advanced regional disease effectively in about one third of patients. In an attempt to bolster regional response rates and address systemic disease that may not be readily apparent, clinicians have shown significant interest in the potential immunologic effects seen when regional treatments are used in conjunction with systemic immunotherapies. This concept of regional treatments generating an abscopal type effect has been described for both intralesional therapy and regional chemotherapy in animal models. ${ }^{8-11}$

Our group and others have proposed and will treat patients with regional chemotherapy (RC) in combination with systemic therapies such as RC combined with melphalan and ipilimumab to help eliminate small-volume metastatic disease outside the field of regional treatment.
Two trials currently are exploring the use of regional therapy in the form of a melphalan-based isolated limb infusion (ILI) and systemic immunotherapy using ipilimumab. The first is a single-center trial that uses ipilimumab several weeks after ILI in the post-regional treatment adjuvant setting (NCT01323517). The second is a multicenter trial that examines the immunologic and clinical responses of patients treated with ipilimumab neoadjuvantly 4-6 weeks before regional ILI treatment with melphalan (NCT02115243).

By inducing tumor cell death, RC can reduce the ability of the tumor to suppress immune responses while simultaneously priming and activating antigen-specific immune cells for tumor cell killing. Similar combination therapies with intralesional therapies are scientifically rational and are currently being explored. One example is a study investigating intra-regional bacillus calmette-guerin (BCG) followed by ipilimumab (NCT01838200). The oncolytic virus, oncoVEXGM-CSF, also is undergoing further evalation in clinical trials (NCT00769704).

Ultimately, the development of IT disease still is to a large degree poorly understood. The study by Read and colleagues highlights that IT disease occurs with relative frequency in node-positive patients and carries a poor prognosis when lymph node involvement is present. In contrast, the prognosis is significantly better for populations with no nodal involvement. Encouraging both of these patient populations to enter clinical trials is critically important to the furtherance of our knowledge concerning melanoma therapeutics. Trial involvement is not only critical due to the poor prognosis of these patients, but more importantly, they are a unique cancer patient population in that the majority have easily accessible tissue for serial superficial biopsies that can be obtained through the course of a clinical trial for correlative science studies. These correlative studies will help provide insight into various treatments not only for better management of regionally advanced disease but also for the development better therapeutic strategies for patients with distant metastatic disease.

\section{REFERENCES}

1. Pawlik TM, Ross MI, Johnson MM, Schacherer CW, McClain DM, Mansfield PF, Lee JE, Cormier JN, Gershenwald JE. Predictors and natural history of in-transit melanoma after sentinel lymphadenectomy. Ann Surg Oncol. 2005;12:587-96. Epub 16 January 2005.

2. Beasley GM, Speicher PJ, Sharma K, Jiang B, Salama AKS, Seigler H, Mosca PJ, Tyler DS. Efficacy of repeat sentinel lymph node biopsy for patients who develop recurrent melanoma. $J$ Am Coll Surg. 2014;218:686-92. Epub 24 December 2013.

3. Ariyan CE, Brady MS. History of regional chemotherapy for cancer of the extremities (review). Int $J$ Hypertherm. 2008;24:185-92. 
4. Raymond AK, Beasley GM, Broadwater G, Augustine CK, Padussis JC, Turley R, Petersen B, Seigler H, Pruitt SK, Tyler DS. Current trends in regional therapy for melanoma: lessons learned from 225 regional chemotherapy treatments between 1995 and 2010 at a single institution. J Am Coll Surg. 2011;213:306-16. Epub 13 April 2011.

5. Jiang BS, Speicher PJ, Thomas S, Mosca PJ, Abernethy AP, Tyler DS. Quality of life after isolated limb infusion for in-transit melanoma of the extremity. Ann Surg Oncol. 2014. doi:10.1245/ s10434-014-3979-9.

6. Sosman JA, Kim KB, Schuchter L, Gonzalez R, Pavlick AC, Weber JS, McArthur GA, Hutson TE, Moschos SJ, Flaherty KT, Hersey P, Kefford R, Lawrence D, Puzanov I, Lewis KD, Amaravadi RK, Chmielowski B, Lawrence HJ, Shyr Y, Ye F, Li J, Nolop KB, Lee RJ, Joe AK, Ribas A. Survival in BRAF V600mutant advanced melanoma treated with vemurafenib. $N$ Engl $J$ Med. 2012;366:707-14.

7. Robert C, Thomas L, Bondarenko I, O’Day S, M D JW, Garbe C, Lebbe C, Baurain JF, Testori A, Grob JJ, Davidson N, Richards J, Maio M, Hauschild A, Miller WH Jr, Gascon P, Lotem M,
Harmankaya K, Ibrahim R, Francis S, Chen TT, Humphrey R, Hoos A, Wolchok JD. Ipilimumab plus dacarbazine for previously untreated metastatic melanoma. $N$ Engl $J$ Med. 2011;364:2517-26.

8. Toomey P, Kodumudi K, Weber A, Kuhn L, Moore E, Sarnaik AA, Pilon-Thomas S. Intralesional injection of Rose Bengal induces a systemic tumor-specific immune response in murine models of melanoma and breast cancer. PLoS One. 2013;8:e68561.

9. Jiang BS, Beasley GM, Speicher PJ, Mosca PJ, Morse MA, Hanks B, Salama A, Tyler DS. Immunotherapy following regional chemotherapy treatment of advanced extremity melanoma. Ann Surg Oncol. 2014;21:2525-31.

10. Ross MI. Intralesional therapy with PV-10 (Rose Bengal) for intransit melanoma (review). J Surg Oncol. 2014;109:314-9. doi: 10.1002/jso.23554. Epub 10 February 2014.

11. Olofsson R, Lindberg E, Karlsson-Parra A, Lindnér P, Mattsson $\mathrm{J}$, Andersson B. Melan-A specific CD8 $+\mathrm{T}$ lymphocytes after hyperthermic isolated limb perfusion: a pilot study in patients with in-transit metastases of malignant melanoma. Int J Hypertherm. 2013;29:234-8. 